\title{
Sinergic Effect of Therapeutic Ultrasound and Low-Level Laser Therapy in the Treatment of Hands and Knees Ostheoarthritis
}

\author{
De Souza Simão ML, Fernandes AC, Casarino RL, Zanchin AL, Ciol H, de Aquino Junior AE* and Bagnato VS
}

Institute of Physics of São Carlos, University of São Paulo, São Carlos, São Paulo, Brazil

*Corresponding author: Antonio Eduardo De Aquino Junior, Institute of Physics of São Carlos, University of São Paulo, PO Box 369, 13560-970, São Carlos, São Paulo, Brazil, Tel: +55 (16) 3373 9810; E-mail: antonioaquino@ifsc.usp.br

Received date: December 13, 2018; Accepted date: December 29, 2018; Published date: December 31, 2018

Copyright: (C) 2018 De Souza Simão ML, et al. This is an open-access article distributed under the terms of the Creative Commons Attribution License, which permits unrestricted use, distribution, and reproduction in any medium, provided the original author and source are credited.

\begin{abstract}
Osteoarthritis is a degenerative joint disease that affects predominantly hands and knees of the elderly population, being characterized by chronic pain and limitation of joint movements. Therapeutic approaches to ease the pain, as low-intensity pulsed ultrasound and photobiomodulation (low-level laser therapy) have been broadly used as a complement to drug treatment of osteoarthritis. The aim of this study was to evaluate the synergic effect of LIPUS associated to LLLT on osteoarthritis of hands and knees. For this, 69 patients, being 48 affected by knee osteoarthritis and 21 affected by hand osteoarthritis were selected for the study. Patients were evaluated by the Western Ontario and McMaster Universities Osteoarthritis Index (WOMAC) for knee osteoarthritis and by Australian Canadian Osteoarthritis Hand (AUSCAN), for hands osteoarthritis. All patients filled out the Visual Analogue Scale (VAS) pain questionnaire, which showed statistical improvement of hands $(p<0.001)$ and knees $(p<0.001)$ when comparing before and after treatment. Functional evaluation by AUSCAN showed improvement of hands functionality $(p<0.002)$. Results showed that the synergic therapy of LIPUS and LLLT were efficient in the treatment of hands and knees osteoarthritis, providing a new approach of a non-pharmacological and non-invasive treatment that contributes to better quality of life for the patients with this chronic and degenerative pathology.
\end{abstract}

Keywords: Osteoarthritis; Low-level laser therapy; Therapeutic ultrasound; WOMAC; AUSCAN

\section{Introduction}

Osteoarthritis is a degenerative rheumatologic condition that affects people over 40 years old, being characterized by chronic pain, loss of joint flexibility, edema and grating sensation [1]. Mechanical and genetics background can contribute to the condition, affecting mostly hands and knees [2,3]. Sore or stiff joint is the most common complaint about osteoarthritis and results in loss of joint strength, impaired mechanical function, loss of flexibility and decreased activity of daily life, which affects directly one's quality of life.

The default non-pharmacological treatment to osteoarthritis consists in monitored physical activities as stretching and strengthening the muscles around the affected joints [4,5], increasing physical conditioning and diminishing the joint action in a singular way, decreasing the pain and increasing quality of life. In addition to that, photobiomodulation (PBM) and therapeutic ultrasound are also used as an approach to decrease pain due to its analgesic and antiinflammatory effect $[6,7]$.

Recent studies produced by the Institute of Physics of São Carlos, University of São Paulo, used a device prototype that simultaneously emitted therapeutic ultrasound and low-level laser for photobiomodulation therapy. This device was responsible for contributing to the analgesic and anti-inflammatory effect as well as enzymatic and mitochondrial modulation produced by the phototherapy associated with up to the cavitation effect produced by the ultrasound, potentializing the treatment $[8,9,10,11]$. The conjugation of both treatments is based on ultrasonic and light field superposition [12,13], resulting in higher analgesic and antiinflammatory effect and stabilizing the cartilage degeneration $[14,15]$.

The objective of this study was to expand the studies based on ultrasound and laser conjugation to treat hands and knee osteoarthritis, presenting a larger sample number and evaluating before and after treatment with this new combined therapeutics technique.

\section{Materials and Methods}

\section{Laser and ultrasound prototype}

The device prototype was designed and assembled by the Technological Support Laboratory of the Institute of Physics of São Carlos, University of São Paulo.

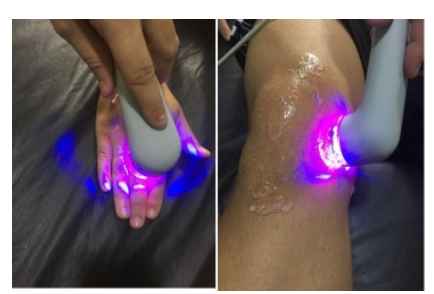

Figure 1: Demonstrative of laser and ultrasound synergic application on phalanx joint and on knee joints.

This prototype allows laser and ultrasound emission simultaneously, overlapping both fields and contributing to the synergic effect caused by both at the tissue (Figure 1). 
Citation: De Souza Simão ML, Fernandes AC, Casarino RL, Zanchin AL, Ciol H, et al. (2018) Sinergic Effect of Therapeutic Ultrasound and LowLevel Laser Therapy in the Treatment of Hands and Knees Ostheoarthritis. J Arthritis 7: 277. doi:10.4172/2167-7921.1000277

Page 2 of 4

\section{Patients and evaluation}

For the study, 69 patients aging 67 years old were selected, being 48 diagnosed with knee osteoarthritis and 21 with hands osteoarthritis. Exclusion factors considered were pre-existence of other chronic and/or degenerative diseases as autoimmune diseases and fibromyalgia and drug infiltration treatment three months prior to the beginning of the project. Patients were evaluated by the Western Ontario and McMaster Universities Osteoarthritis Index (WOMAC) questionnaire for knees osteoarthritis and by the Australian Canadian Osteoarthritis Hand (AUSCAN) questionnaire for hands osteoarthritis. All evaluations were performed before and right after each treatment session.
For hands osteoarthritis, the box and block test - defined as block displacement by manual manipulation which measures the functional capacity, is defined by the number of blocks displaced after manipulation - was applied.

\section{Intervention protocol}

Intervention protocol was applied twice a week, totalizing 8 sessions, both in hands and knees osteoarthritis groups. The parameters set up are described in Table 1.

\section{Parameters set up for hands osteoarthritis treatment}

Ultrasound: Pulsed, frequency $1 \mathrm{MHZ}, 100 \mathrm{~Hz}, 50 \%$ of working cycle and spatial average temporal average (SATA) of $0,5 \mathrm{w} / \mathrm{cm}^{2}$; Laser: Wavelength $660 \mathrm{~nm}$, continuous, $100 \mathrm{~mW}$ and power density of $60 \mathrm{~mW} / \mathrm{cm}^{2}$. Application time: 6 minutes for each hand.

\section{Parameters set up for knees osteoarthritis treatment}

Ultrasound: Pulsed, frequency $1 \mathrm{MHZ}, 100 \mathrm{~Hz}, 50 \%$ of working cycle and spatial average temporal average (SATA) of $0,5 \mathrm{w} / \mathrm{cm}^{2}$; Laser: Wavelength $660 \mathrm{~nm}$, continuous, $100 \mathrm{~mW}$ and power density of $60 \mathrm{~mW} / \mathrm{cm}^{2}$. Application time: 8 minutes for each hand.

Table 1: Therapeutic ultrasound and laser parameters set up for the treatment of hands and knees osteoarthritis.

\section{Results}

The patients of the study were evaluated according to pain index and joint functionality. The tests used for the analyses (VAS, WOMAC, AUSCAN and BOX AND BLOCK TEST) showed statistical difference after treatment when compared to the initial stage.

Figure 2 shows the Visual Analogue Scale (VAS) of both knee and hands osteoarthritis patients, indicating significant pain relief of knee osteoarthritis $(\mathrm{p}<0.001)$ as well as osteoarthritis of hands $(\mathrm{p}<0.001)$.

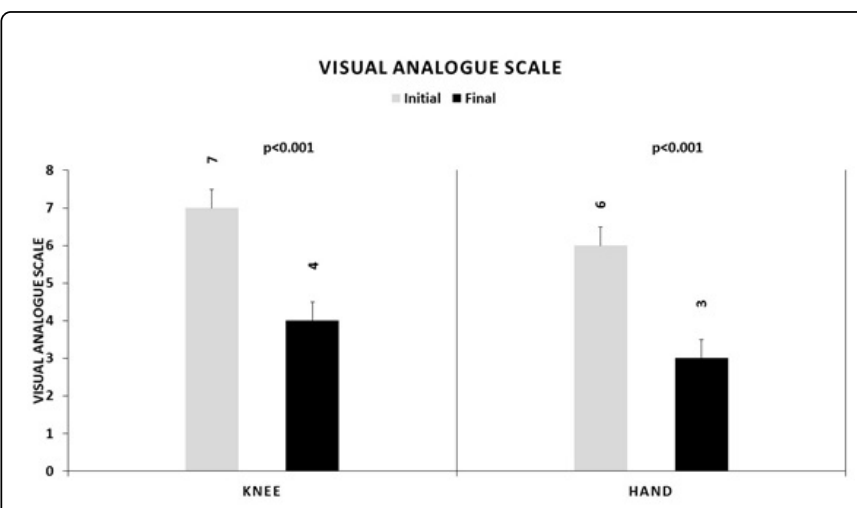

Figure 2: Comparative of visual analogue scale (VAS) of patients with hands or knees osteoarthritis before and after treatment with the simultaneous application of therapeutic ultrasound and photobiostimulation (laser). Values are expressed as mean value and standard deviation. For knee and hands osteoarthritis, the VAS analysis was significantly different $(\mathrm{p}<0.001)$ according to " $\mathrm{t}$ " Student test for $\mathrm{p}<0.05$.

The WOMAC evaluation, specific for knee osteoarthritis, indicated improvement of joint functionality when comparing before and after treatment $(\mathrm{p}<0.0001)$ (Figure 3).

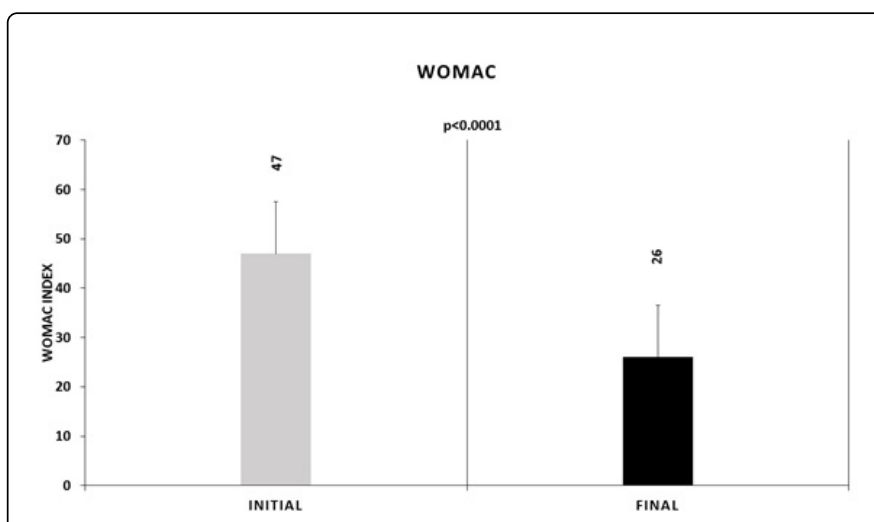

Figure 3: Comparative of the WOMAC test before and after treatment of patients with knee osteoarthritis treated with the simultaneous application of therapeutic ultrasound and photobiostimulation (laser). Values are expressed as mean value and standard deviation. For knee osteoarthritis, the analysis was significantly different $(\mathrm{p}<0.001)$ according to " $\mathrm{t}$ " Student test for $\mathrm{p}<0.05$.

The AUSCAN questionnaire, specific for hands osteoarthritis, showed a significant improvement of joint functionality $(\mathrm{p}<0.002)$ when comparing patients' condition before and after treatment (Figure $4)$. 


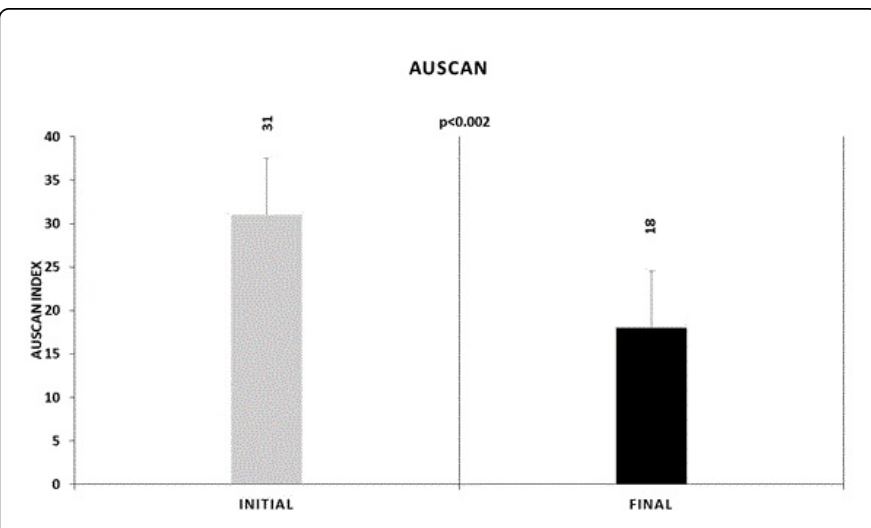

Figure 4: Comparative of AUSCAN questionnaire of patients with hands osteoarthritis after treatment with simultaneous application of therapeutic ultrasound and photobiostimulation (laser). Values are expressed as mean value and standard deviation. For hands osteoarthritis, the analysis was significantly different $(\mathrm{p}<0.002)$ according to " $\mathrm{t}$ " Student test for $\mathrm{p}<0.05$.

The box and block test analyses showed improvement of hands functionality after treatment, with $\mathrm{p}<0.02$ for right hand and $\mathrm{p}<0.07$ for left hand. Although left hand improvement did not show statistical difference for $\mathrm{p}<0.05$, the patient's improvement should be emphasized since the condition after treatment represents improvement of $15.9 \%$ when compared to the initial time (Figure 5).

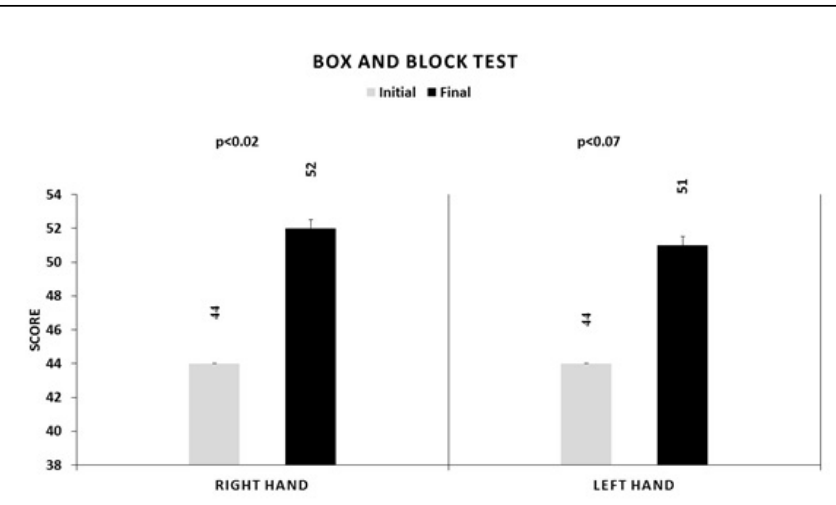

Figure 5: Comparative of box and block test of patients with hands osteoarthritis before and after treatment with simultaneous application of therapeutic ultrasound and photobiostimulation (laser). Values are expressed as mean value and standard deviation. For right hand, the analysis showed statistical difference of $\mathrm{p}<0.02$. Although no statistical difference was found for left hand when comparing before and after treatment $(\mathrm{p}<0.07)$, the functional gained by the patients should be emphasized. Analyses according to " $\mathrm{t}$ " Student test for $\mathrm{p}<0.05$.

\section{Discussion}

Osteoarthritis is a chronic degenerative condition of the joints that increases constantly in the Brazilian population due to changes in pattern of population age pyramid. New therapeutic approaches are constantly being proposed worldwide to the treatment of osteoarthritis, aiming to improve the patient's quality of life.

Several reports state that therapeutic ultrasound and low-level laser therapy brings benefits to osteoarthritis patients [16,17], since photobiomodulation can increase anti-inflammatory activity and analgesic effect, resulting in reduction of joint pain. Still, it is stated that both therapeutic approaches promote stabilization of articular cartilage degeneration $[14,15]$.

The present study shows the synergic effect when using therapeutic ultrasound and photobiomodulation in patients with knee or hands osteoarthritis. Questionnaires and functional tests proved to be essential to quantify the patient's improvement after treatment.

As observed in Figure 3, the VAS questionnaire allowed to evaluate the pain index of the patient, both for hands and knees osteoarthritis. Analyzing the results, it is possible to observe that pain, the most limiting complaint about osteoarthritis, was significantly reduced for both hands $(\mathrm{p}<0.001)$ and knee osteoarthritis $(\mathrm{p}<0,001)$.

Questionnaires WOMAC and AUSCAN, specific for knee and hands osteoarthritis, respectively, showed results of joint functional activity. It was observed improvement of joint functionality for both groups (hands, $\mathrm{p}<0.002$; knee, $\mathrm{p}<0.0001$ ) when comparing before and after treatment. Still, the hand group was submitted to Box and Block test to evaluate hands strength and block movements in hand joints during manipulation. The reduction of pain was observed in both hands, but only the right hand had a statistically significant improvement $(\mathrm{p}<0.02)$, while left hand showed a percentual improvement of $15.9 \%$.

Previous studies of our group [8-13] showed the synergic effect of therapeutic ultrasound and photobiomodulation (low-level laser therapy) in anti-inflammatory and analgesic modulation as a better approach than using individual therapeutic alone. The use of lowintensity pulsed ultrasound to the treatment of osteoarthritis stimulates cartilage growth and proliferation of chondrocytes, apart from stimulating anti-inflammatory response and analgesic effect with no significant thermic action associated $[10,18,19,20]$, being the mechanical effect of ultrasound the major contributor to pain relief [21]. The thermic effect on cells can result in higher metabolism, higher blood flow and reduced chronic and subacute inflammation. Structural effects consist in collagen extensibility of tendons, ligaments and joint capsule and connective tissue contracture.

The longitudinal vibration caused by pulsed ultrasound waves results in a negative pressure onto cells, which cause cell organelles and biomolecules to increase cell metabolism and results in higher blood flow through the blood vessels, consequently increasing local temperature and oxygen supply [21,22]. This additional heat can be converted to mechanical and electrical energy inside cells, increasing molecular movements. It was observed that muscles cell can absorb this energy source faster than adipose tissue $[23,24]$. The non-thermic physical effects can promote cell permeability, protein synthesis and ionic exchange through the cellular membrane, increasing tissue repair. [25]. Still, the increase of vascular permeability and cell metabolism contribute to analgesic effect by normalizing the thermodynamic mechanisms involved in pain and mechanoreceptors $[12,26,27]$.

Photobiomodulation can promote cartilage regeneration by stimulating chondrocytes proliferation and extracellular matrix synthesis and secretion $[28,29]$, contributing to higher blood flow, 
Citation: De Souza Simão ML, Fernandes AC, Casarino RL, Zanchin AL, Ciol H, et al. (2018) Sinergic Effect of Therapeutic Ultrasound and LowLevel Laser Therapy in the Treatment of Hands and Knees Ostheoarthritis. J Arthritis 7: 277. doi:10.4172/2167-7921.1000277

Page 4 of 4

reduced edema and increase in tissue oxygen supply, contributing to physiological mechanisms dependent of photochemical actions at cell level by increasing the release of neurotransmitters involved in pain modulation, as serotonin [30].

Thus, the present study highlights the importance of the new technological device in treatment of osteoarthritis as an alternative to pharmacological treatment of a chronic and degenerative disease, contributing to increase the patients' quality of life.

\section{Conclusion}

The ultrasonic and photonic technology combined showed to be a great therapeutic approach in the treatment of hands and knee osteoarthritis, resulting in relief of pain and increase in joint functional movements. These results encourage the investigation of using the combined ultrasound and laser technology to treat other chronical joint diseases of shoulders, spine and hip and study the benefits it could bring to post-operational rehabilitation.

\section{Ethical Approval}

The study was approved by the Hospital Ethical Committee (resolution 466/2012).

\section{Funding}

This search was supported in part by CNPq (INOF-INCT grant (573587/2008-6); FINEP (grant 01.13.0430-00) and São Paulo Research Foundation (FAPESP) grant 2013/07276-1 (CePOF).

\section{Conflicts of Interest}

All authors confirm that there is no conflict of interest.

\section{References}

1. Pereira D, Ramos E, Branco J (2015) Osteoarthritis. Acta Med Port 28: 99-106.

2. Burgos-Vargas R, Cardiel MH, Loyola-Sánchez A, De Abreu MM, PonsEstel BA, et al. (2014) Characterization of Knee Osteoarthitis in Latin America. A Comparative Analysis of Clinical and Health Care Utilization in Argentina, Brazil and Mexico. Reumatol Clin 10: 152-159.

3. Zhang W, Doherty M, Leeb BF, Alekseeva L, Arden NK, et al. (2007) EULAR evidence based recommendations for themanagement of hand osteoarthitis: reporto f Task Force of EULAR Standing Committee for International Clinicial Studies Including Therapeutics (ESCIST). Ann Rheum Dis 66: 377-388.

4. $\quad$ Abbasi J (2017) Can Exercise Prevent Knee Osteoarthritis? Jama 318: 2169-2171.

5. Kirihara RA, Catelan FB, Farias FES, Silva CACD, Cernigoy CHA, et al. (2017) Intensity, duration and type of physical activity required to improve function in knne osteoarthritis. Acta Ortop Bras 25: 25-29.

6. Yeğin T, Altan L, Kasapoğlu Aksoy M (2017) The Effect of Therapeutic Ultrasound on Pain and Physical Function in Patients with Knee Osteoarthritis. Ultrasound Med Biol 43: 187-194.

7. Jang H, Lee $H$ (2012) Meta-Analysis of pain relief effects by laser Irradiation on joint áreas. Photomed Laser Surg 30: 405-417.

8. Jorge AES, Simão MLd, Fernades AC, Chiari A, de Aquino Jr AE, et al. (2018) Ultrasound conjugated with Laser Therapy in treatment of osteoarthritis: A case study. J Sports Med Ther 3: 024-027.

9. Jorge AES, Simão MLS, Fernades AC, Chiari A, de Aquino Junior AE, et al. (2017) Can Combined Ultrasound and Laser Therapy Potentiate the
Treatment of a Symptomatic Osteoarthritis? A Case Report. J Nov Physiother 7: 372 .

10. Paolillo AR, Paolillo FR, João JP, João HA, Bagnato VS (2015) Synergic effects of ultrasound and laser on the pain relief in women with hand osteoarthritis. Lasers Med Sci 30: 279-286.

11. Paolillo FR, Paolillo AR, João JP, Frascá D, Duchêne M, et al. (2018) Ultrasound plus low-level laser therapy for knee osteoarthritis rehabilitation: a randomized, placebo-controlled trial. Rheumatol Int 38: 785-793.

12. Amaral J, Franco DM, de Aquino Junior AE, Bagnato VS (2018) Fibromyalgia Treatment: A New and Efficient Proposal of Technology and Methodological - A Case Report. J Nov Physiother 8: 379.

13. Amaral J, Franco DM, de Aquino Junior AE, Bagnato VS (2018) Could Hands be a New Treatment to Fibromyalgia? A Pilot Study. J Nov Physiother 8: 393.

14. Walter SG, Ossendorff R, Schildberg FA (2018) Articular cartilage regenetarion and tissue engineering models: a systematic review. Arch Orthop Trauma Surg.

15. Mora JC, Przkora R, Cruz-Almeida Y (2018) Knee osteoarthritis: pathophysiology and current treatment modalities. 11:2189-2196.

16. Loyola-Sánchez A, Richardson J, MacIntyre NJ (2010) Efficacy of ultrasound therapy for the management of knee osteoarthritis: a sytematic review with meta-analysis. Osteoarthritis Cartilage 18: 1117-1126.

17. Rodriguez-Merchan EC (2016) Conservative treatment of acute knee osteoarthritis: A review of the Cochrane Library. Journal of Acute Disease 5: 190-193.

18. Tascioglu F, Kuzgun S, Armagan O, Ogutler G (2010) Shortterm effectiveness of ultrasound therapy in knee osteoarthritis. J Int Med Res 38: 1233-1242.

19. Sánchez AL, Wakamatzu MAR, Zamudio JV, Casasola J, Cuevas $\mathrm{CH}$, et al. (2009) Effect of low-intensity pulsed ultrasound on regeneration of joint cartilage in patients with second and third degree osteoarthritis of the knee. Reumatol Clin 5: 163-167.

20. Huang MH, Yang RC, Lee CL, Chen TW, Wang MC (2005) Preliminary results of integrated therapy for patients with knee osteoarthritis. Arthritis Rheum 53: 812-820.

21. Kitchen SS, Partridge CJ (1990) A review of therapeutic ultrasound: I. Background, physiological effects and hazards. Physiotherapy.

22. Machado CM (1991) Ultra-som. In: Eletroterapia prática. 2nd edtn, São Paulo, Pancast.

23. Partridge CJ (1987) Evaluation of ultrasound therapy devices. Physiotherapy 73: 166-168.

24. Kitchen S, Bazin S (1996) Eletroterapia de Clayton. 10th edtn, São Paulo, Manole.

25. Low J, Reed A (2001) Ultrassom terapêutico. In:_Eletroterapia aplicada: princípios e prática. São Paulo, Manole.

26. Drape DO, Sunderland S, Kirkendall DT, Ricard M (1993) A comparison of temperature rise in human calf muscles following applications of underwater and topical gel ultrasound. J Orthop Sports Phys Ther 17: 247-251.

27. Holdcroft A, Jaggar S (2005) Core topics in pain. Cambridge University Press, Cambridge.

28. Ruiz Calatrava I, Santisbetan Valenzuela JM, Gómez-Villamandos RJ, Redondo JI, Gómez-Villamandos JC, et al. (1997) Histological and clinical responses of articular cartilage to low-level laser therapy: Experimental study. Lasers Med Sci 12: 117-121.

29. Jia YL, Guo ZY (2004) Effect of low-power He-Ne laser irradiation on rabbit articular chondrocytes in vitro. Lasers Surg Med 34: 323-328.

30. Hegedus B, Viharos L, Gervain M, Galfi M (2009) The effect of low-level laser in knee osteoarthritis: A Double-blind, randomized, placebocontrolled trial. Photomed Laser Surg 27: 577-584. 